\title{
The role of traditional leaders in preventing and addressing sexual and gender-based violence: Findings from KwaZulu-Natal, Northwest and Limpopo provinces in South Africa
}

\author{
Mantshi Teffo-Menziwa \\ Population Council \\ Saiqa Mullick \\ Population Council \\ Prince Cedza Dlamini
}

Follow this and additional works at: https://knowledgecommons.popcouncil.org/departments_sbsr-rh

Part of the Community-Based Research Commons, International Public Health Commons, Public Health Education and Promotion Commons, and the Women's Health Commons How does access to this work benefit you? Let us know!

\section{Recommended Citation}

Teffo-Menziwa, Mantshi, Saiqa Mullick, and Prince Cedza Dlamini. 2010. "The role of traditional leaders in preventing and addressing sexual and gender-based violence: Findings from KwaZulu-Natal, Northwest and Limpopo provinces in South Africa," Final report. Johannesburg: Population Council. 


\section{The Role of Traditional Leaders in Preventing and Addressing Sexual and Gender-Based Violence:}

Findings from KwaZulu-Natal, Northwest and Limpopo Provinces in South Africa 



\section{The Role of Traditional Leaders in Preventing and Addressing Sexual and Gender-Based Violence:}

\section{Findings from KwaZulu-Natal, North West and Limpopo Provinces in South Africa}

Compiled by:

Population Council

Mantshi Teffo-Menziwa

Saiqa Mullick

Ubuntu Institute

Prince Cedza Dlamini 
This report is made possible by the President's Emergency Plan for AIDS Relief and the generous support of the America people through the United States Agency for International Development (USAID) under the terms of USAID Cooperative Agreement No. 674-A-00-08-00002-00. The contents are the responsibility of the Population Council and Ubuntu Institute and do not necessarily reflect the views of USAID or the United States Government.

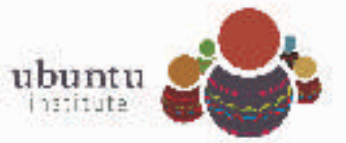

The Ubuntu Institute is a registered non-profit organisation in South Africa looking at the role of culture, heritage and indigenous knowledge systems in achieving the Millennium Development Goals in Africa. The Institute works in the following Southern African Development Community (SADC) countries: South Africa, Swaziland, Lesotho, Zambia, Botswana and Ghana. The Institute focuses on HIV and AIDS, gender equality and the empowerment of women and youth, economic development and entrepreneurship, education and environmental sustainability.

(2) Population Council

The Population Council is an international, non-profit, non-governmental organisation that seeks to improve the well-being and reproductive health of current and future generations around the world and to help achieve a humane, equitable, and sustainable balance between people and resources. The Council conducts research in three areas: HIV and AIDS, poverty, gender, youth, and reproductive health.

www.popcouncil.org www.popcouncil.org/topics/gbv.asp

Copyright October 2010 The Population Council Inc.

This document may be reproduced in whole or part without permission of the Population Council provided full source citation is given and the reproduction is not for commercial purposes. 


\section{Acknowledgements}

The Population Council would like to extend its gratitude and appreciation to Ubuntu Institute for their strategic partnership, expert advice, co-ordination and organisation in making this programme, community social mobilisation events and capacity building workshops possible in KwaZulu-Natal, North West and Limpopo provinces.

We are grateful and indebted to the Traditional Leaders who shared their views and grassroots experiences on the socio-cultural factors influencing sexual assault and domestic violence and ways to improve strategies to address sexual assault and domestic violence.

We are also grateful to our partners in the provinces: The Department of Health (DOH), Department of Justice (DOJ) and NGOs that participated and provided much needed capacity building for Traditional Leaders.

We also thank LCC Capital Consulting and Leonie Selvan Communications for their assistance in compiling and producing this report. 


\section{Table of Contents}

Acronyms

Executive Summary

1

Introduction

3

Methodology and Data Analysis Process

5

Programme Activity 1:

8

Sexual and Gender-based Violence Workshops

Programme Activity 2:

Capacity Building

Summary of Findings and Recommendations

20

Conclusion

23

Bibliography 


\section{Acronyms}

AIDS

CPF

CONTRALESA

DOH

DOS

DOJ

DPLG

GBV

HIV

HTT

IDU

IEC

MARPS

MTCT

NGO

NPO

PEPFAR

PMTCT

SAPS

SGBV

SRH

STIS

UN

USAID

HCT
Acquired Immune Deficiency Syndrome

Community Policing Forum

Congress of Traditional Leaders in South Africa

Department of Health

Department of Social Welfare and Development

Department of Justice

Department of Provincial and Local Government

Gender-based Violence

Human Immune Virus

Hoedspruit Training Trust

Intravenous Drug Use

Information, Education and Communication

Most-At-Risk-Populations

Mother-to-Child Transmission

Non-Governmental Organisation

Non-Profit Organisation

President's Emergency Plan for AIDS Relief

Prevention of Mother-to-Child Transmission

South African Police Service

Sexual and Gender-based Violence

Sexual Reproductive Health

Sexually Transmitted Infections

United Nations

United States Agency for International Development

HIV Counselling and Testing 


\section{Executive Summary}

\section{0}

The Population Council, in partnership with the Ubuntu Institute, embarked on a programme to engage Traditional Leaders in three South African provinces (North West, KwaZulu-Natal and Limpopo to address sexual and gender-based violence (SGBV) in rural communities. The overarching goals of the programme were to strengthen linkages between the Population Council and traditional communities, generate and share strategic information on SGBV, strengthen prevention and response to child sexual assault, engage new partners to address prevention of and access to SGBV services, and expand access to comprehensive post-rape services by working with Traditional Leadership structures.

Traditional Leadership is one of the oldest institutions in South Africa and is recognised by the South African Government through the Traditional Leadership and Governance Framework Act, 2003 (Act No. 41 of 2003). However, the positions of Traditional Leadership are determined by custom and are inherited.

Traditional Leaders are influential in most rural communities in southern Africa and play a key role in advocating and driving social mobilisation initiatives that address HIV and AIDS and sexual gender-based violence ${ }^{1}$. Traditional Leaders preside over customary law courts that exercise legislative power and which maintain law and order in communities at grassroots level. Traditional Leaders reach thousands of people in their communities through "imbizos/lekgotlas" or community dialogues; they advise government on traditional affairs and influence policy making that affects the lives of millions of people in mostly rural populations.

The National House of Traditional Leaders was established through the National House of Traditional Leaders Bill of 2008. The house is comprised of three senior Traditional

\section{Traditional Leaders reach}

thousands of people in their

communities through "imbizos/

lekgotlas" or community

dialogues; they advise government

on traditional affairs and influence

policy making that affects the lives

of millions of people in mostly

rural populations.

Leaders elected by each provincial house. These institutions have been established in all nine provinces in South Africa and are recognised as key partners in the fight against HIV and AIDS and in the implementation of the 2007-2011 South African National HIV and AIDS strategic plan $^{2}$.

The Limpopo, KwaZulu-Natal and North West provinces were selected because of the high prevalence of HIV and AIDS and SGBV. The Department of Health, various nongovernment organisations (NGOs), the Department of Justice, members of the National House of Traditional Leaders and the Congress of Traditional Leaders in South Africa (CONTRALESA) were key partners in this programme at a provincial level.

The programme aimed to:

- Explore understanding and perceptions of sexual and gender-based violence amongst Traditional Leaders in KwaZulu- Natal, North West and Limpopo through a consultative process. 
- Drive social mobilisation campaigns to address community cultural norms, values and social practices pertaining to SGBV in KwaZulu-Natal, North West and Limpopo.

- Identify socio-cultural issues that influence a broader understanding of the law that governs gender-based violence and its intersection with customary law.

- Develop capacity among Traditional Leaders on sexual and gender-based violence to increase their understanding and knowledge.

The key outcomes of the programme reflect a variety of cross-cutting lessons that can inform future SGBV prevention and response activities with Traditional Leaders:

- Traditional Leaders are still largely uninformed about the drivers of SGBV in South Africa and need further capacity building.

- Traditional Leaders need to work closely with local government officials and other government agencies to support the empowerment of women in their communities, engagement of men, and to sensitise their communities about SGBV.

- Through social mobilisation campaigns, Traditional Leaders can play a vital role in strengthening prevention and responses to SGBV as they reach thousands of people in their communities at a grassroots level. They are willing to support such campaigns.

- Female Traditional Leaders remain an untapped resource in rural communities that expand access to services for young girls. Female Traditional Leaders can help to create "an enabling environment" for increased reporting, referral and support of SGBV cases.

- Female Traditional Leaders are a key access point at community level to provide and share information on
SGBV thus strengthening prevention and responses to child sexual assault cases.

- Traditional Leaders need protocols and guidance documents which they regard as a critical component for effective and comprehensive programming.

- Quality SGBV programming tools are needed for community interventions. Traditional Leaders consistently expressed the need for validated, Africarelevant training curricula, monitoring and evaluation (M\&E) tools.

- Traditional Leaders would like to document best practices that are effective in fighting HIV and AIDS in their communities.

- Traditional Leaders need to be better linked to the justice system and to the South Africa Police Service (SAPS) to be able to more effectively deal with perpetrators.

- Traditional Courts are an important platform for addressing and adjudicating gender-based violence cases in rural communities and need to be revived or strengthened where they already exist.

- Traditional Leaders need to collaborate with farm owners to support the enforcement of the traditional court systems in farming communities where appropriate.

The main limitation to addressing the issues identified in the capacity building and research workshops was systematic gender inequity. All workshops were attended by a majority of men. Since it is mostly men who are appointed as Traditional Leaders, a conscious effort needs to be made to enlist female Traditional Leaders (wives of chiefs) in future. 


\section{Introduction}

Southern Africa is currently the region in the world most affected by HIV and AIDS. In nine countries in southern Africa, $12 \%$ or more of adults aged 15-49 are living with HIV or AIDS, making those countries the highest prevalence countries in the world (UNAIDS, 2008). UNAIDS (2008) estimated that southern Africa accounted for $35 \%$ of HIV infections and $38 \%$ of AIDS deaths globally in 2007. HIV epidemics in southern Africa are highly generalised, with HIV most commonly transmitted through heterosexual intercourse. The $\mathbf{2 0 0 9}$ mid-year population estimates that approximately $10.6 \%$ of the total population of South Africa is HIV-positive and "relationship power inequity and intimate partner violence increase the risk of HIV infection in young South African women"³.

Traditional African leaders have always played an important role in the lives of the majority of Africans, especially in rural areas. In South Africa, a White Paper drafted by the Department of Provincial and Local Government in 2000 to formulate a consistent government policy regarding the role and status of Traditional Leaders was later incorporated into the Constitution. This document defined the functions of Traditional Leaders as follows:

- Acting as head of the Traditional Authority (and as such exercising limited legislative power and certain executive and administrative powers);

- Presiding over customary law courts and helping to maintain law and order;

- Assisting members of the community in their dealings with the state;

- Advising government on traditional affairs;

- Convening meetings to consult with communities on needs and priorities and providing information;
- Protecting cultural values and instilling a sense of community in their areas;

- Being the symbols of unity and spokespersons for their communities;

- Being custodians and protectors of the community's customs and general welfare.

Traditional Leaders emphasise the importance of traditional culture and common heritage and are expected to ensure that community members live in harmony with one another. The influence of Traditional Leaders on their communities prevails despite the forces of modernity, changing governmental structures, modernisation, urbanisation, and encroaching Western influences. Traditional Leaders therefore have the potential to play a positive role in addressing the socio-cultural factors that can either fuel or mitigate the spread of HIV in southern Africa.

The links between HIV and sexual and gender-based violence (SGBV) are well established. Men who rape and are physically violent

towards partners are more likely to engage in sexual risk-taking behaviour than other men and this has raised a concern that they are more likely to be infected with HIV 
The links between HIV and sexual and gender-based violence (SGBV) are well established. Men who rape and are physically violent towards partners are more likely to engage in sexual risk-taking behaviour than other men and this has raised a concern that they are more likely to be infected with $\mathrm{HIV}^{4}$. This link has ignited debate and triggered in-depth discussions of how communities can fight SGBV using African cultural values and systems.

SGBV in its various forms is widespread in communities around the world, cutting across class, race, age, religion and national boundaries. The term sexual and genderbased violence broadly refers to the physical, emotional, mental or sexual abuse of a person irrespective of their gender ${ }^{4}$. Sexual assault is acknowledged as a public health issue in South Africa. It is predominantly women and children who suffer the most from SGBV. One of the most recognised causes of SGBV in southern Africa is the traditional imbalance of power between men and women. However, studies have shown that the number of reported cases do not paint a clear picture of the actual incidence of SGBV in communities because, besides the fact that a large proportion of cases of SGBV towards women and children go unreported, men are less likely to report cases of abuse because they are traditionally superior and cannot show vulnerabilities. Moreover, sexual abuse of males particularly at the hands of females is generally misunderstood.

The literature review on sexual and gender-based violence conducted by the Population Council in $2008^{5}$ reveals that one of the societal factors that contribute to higher rates of SGBV is "weak community sanctions against perpetrators," thus highlighting the important role that communities play in the fight against SGBV and HIV and AIDS. Many communities in rural South Africa pay allegiance to a Traditional Leader. As the term implies, a Traditional Leader in the African context is inherently a figurehead associated with African traditions, cultural practices and customary law. Traditional Leaders thus have the influence to promote positive behaviour change, play a pivotal role in educating youth on HIV and AIDS, promote sexual reproductive health rights in the community and within the patriarchal Traditional Leadership; and apply customary law in traditional courts that can begin reversing the epidemic trends of SGBV especially in rural communities.

Despite this, the role of Traditional Leaders in the fight against SGBV and HIV and AIDS in southern Africa has remained limited. This programme seeks to bridge this gap and engage Traditional Leadership and its structures through a multi-sectoral approach. As the President of the Population Council, Peter Donaldson states, "efforts to fight sexual and gender-based violence and address broader sexual reproductive health rights issues will fail without the collaboration of a variety of key partners collaborations with national institutions, distinguished researchers, advocates, policymakers, programme managers, etc." ${ }^{6}$

The programme sought to:

1. Explore the understanding and perceptions of SGBV amongst Traditional Leaders in KwaZulu-Natal, North West and Limpopo through a consultative process.

2. Drive social mobilisation campaigns to address community and cultural norms, values and social practices pertaining to SGBV in KwaZulu-Natal, North West and Limpopo.

3. Identify socio-cultural issues that influence the broader understanding of the law that governs gender-based violence and its intersection with customary law.

4. Develop capacity among Traditional Leaders on SGBV by increasing their understanding and knowledge. 


\section{Methodology and Data Analysis Process}

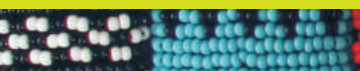 \\ Selection of provinces}

KwaZulu-Natal, North West and Limpopo were selected based on their prominent Traditional Leadership, the rural nature of the provinces and the relationship and technical assistance Population Council has provided to these provinces. In Limpopo, Population Council developed a nurse-driven comprehensive model for post-rape care, and engaged the farming community, through Hlokomela Training Trust to establish sexual assault services in the farming community. In KwaZulu-Natal, Population Council provided technical assistance to conduct a baseline assessment of sexual assault services, which provided evidence to the province of the interventions necessary to strengthen sexual assault services. North West was selected in response to the provincial request for technical support on the engagement of Traditional Leaders in sexual assault care.

The HIV prevalence in these three provinces also contributed to the decision to engage Traditional Leaders there about SGBV. According to the antenatal survey conducted by the Department of Health in 2008, KwaZuluNatal still has the highest HIV prevalence followed closely by Mpumalanga, Free State and North West with overall prevalence greater than 30\%. Gauteng, Limpopo and the Eastern Cape have prevalence rates between 20\% and 30\% and Northern Cape and Western Cape provinces have the lowest prevalence of below 20\%. Research found that $29 \%$ of farm workers in the Hoedspruit community in Limpopo are infected with HIV; a prevalence rate that is considerably higher than that of the general population of the province.

\section{Identification of Traditional Leaders}

Traditional Leaders were identified through the local Traditional Leader's organisations in each province such as the House of Traditional Leaders and Congress of Traditional Leaders in South Africa (CONTRALESA). Population Council contracted a consultant who is a Traditional Leader to help identify Traditional Leaders for the focus group discussions (FGDs) and the capacity building workshops. This strategy was used to bypass protocols within the patriarchal structures which often impede access to the Traditional Leadership.

\section{Focus group discussions}

Focus Group Discussions (FGDs) were conducted with Traditional Leaders to gather information Traditional Leaders about their perceptions of and attitudes to SGBV and to establish what roles Traditional Leaders believe they can play in fighting SGBV in their communities. The FGDs sought to understand individual and community perceptions and cultural norms regarding gender-based violence. The FGDs also aimed to establish what structural issues exist that support or mitigate against gender-based violence. Population Council, in collaboration with the Department of Health conducted three province-specific FGDs with 35 Traditional Leaders - 15 from KwaZulu-Natal, 10 from North West and 10 from Limpopo.

The purpose and objectives of the study were explained to the participants at the start of the FGD and confidentiality was ensured. Each participant signed a consent form and was required to fill in basic socio-demographic data. Each focus group was audio taped with participant permission, and each session lasted about 45-90 minutes. Detailed notes of each session were taken. Participants were encouraged to speak freely and described their experience and perceptions of SGBV. 
A structured questionnaire developed by Population Council and Ubuntu Institute, and translated into Tswana and Zulu, was used during the session to communicate clearly with the target audience. The questionnaire assessed Traditional Leaders' personal understanding of SGBV; the level of community understanding and involvement in SGBV at a preventative and intervention level; Traditional Leaders' understanding of what structures exist in the community to deal with SGBV as well as the interface between community structures and customary laws.

Data collected through the FGDs determined the kind of capacity building that the Traditional Leaders required in order to be active and effective in combating SGBV in their communities. The DOH and other NGO representatives facilitated the sessions. The FGDs were tape-recorded and transcribed verbatim.

\section{Focus group discussion questionnaire}

In their provincial groups, Traditional Leaders discussed a set of questions that were meant to determine:

- The Traditional Leaders' level of understanding of SGBV at a personal level;

- The level of community understanding and involvement in SGBV both at the preventative and intervention levels;

- What structures exist in the community to deal with SGBV and the interface between the structures in the community and customary laws.

The focus group discussions were led by facilitators who used the following set of questions to guide the discussions:

\section{Individual perceptions of SGBV:}

1. What does GBV mean to you?

2. Who is affected by GBV in your community?

3. Why does it happen?

4. How does it contribute to the spread of HIV and AIDS?

5. How are victims of GBV dealt with in your community?

6. How are perpetrators dealt with?

7. What role do traditional leaders play in GBV?

8. What solutions would you propose for GBV in your community?

\section{Community/Cultural norms}

1. What is being done regarding GBV and HIV in initiations, circumcision and virginity testing?

What organisations in your community are involved in prevention and interventions of GBV and HIV?

2. Are you working in partnership with these? Why or why not?

3. How does your community respond to GBV/AIDS?

4. What messages do you give on GBV and AIDS?

5. What role do the media play in your community?

6. What is missing in dealing with GBV/HIV in your community?

\section{Structural issues}

1. How do Traditional Courts work in relation to GBV/HIV?

2. How do these relate to the laws on GBV/HIV in South Africa?

3. How effective are these courts?

4. Why do some cases not go to court?

5. Do you work with the police in your community?

6. How effective is the partnership?

7. What is missing in dealing with GBV and HIV in the legal framework? 


\section{Capacity building}

Population Council provided technical assistance for three two-day capacity building sessions conducted with 126 Traditional Leaders from KwaZulu-Natal, North West and Limpopo. The capacity building sessions aimed to help Traditional Leaders reinforce their traditional role within their communities, equip them with the knowledge and skills to advise their communities correctly, and to deal with social problems where possible, thus relieving the burden on the justice system. Participants were invited to the workshop via various Traditional Leaders' organisations. Attendance was voluntary. The sessions were presented in English, Tswana, Zulu and North Sotho.

The Traditional Leader's general knowledge on SGBV and HIV was assessed prior to the formal presentations on the extent of sexual assault, mother-to-child transmission (MTCT), GBV and HIV and AIDS in each province and the Traditional Court Council Bill and implications for

\section{"As a woman I am proud to be} seen as a key role player in the fight against this bad thing. I will go back to my village and my school and teach my people that this thing of domestic violence is bad and not good for us. I will help my people to understand how to address this issue," (female Traditional Leader,
Traditional Courts. Responses were indicative of the need for more capacity building and mentoring of Traditional Leaders. One such example was the response of an elderly female traditional leader who said that a child in utero feeds on the father's sperm.

The workshops were well received and there was commitment towards further empowerment: "I believe that what is happening is a good thing. Population Council and Ubuntu together with Hlokomela teach us how we should address this issue of gender-based violence. As a woman I am proud to be seen as a key role player in the fight against this bad thing. I will go back to my village and my school and teach my people that this thing of domestic violence is bad and not good for us. I will help my people to understand how to address this issue,"' (female Traditional Leader, Limpopo).

\section{Data analysis process}

All submissions were recorded during the focus group discussions and plenary session and analysed for content and relevance, and validated where necessary through desk research. Initial analysis was conducted on a provincial basis, and thematic analysis was then conducted to explore the similarities and differences across the various provinces.

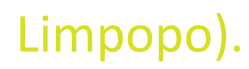




\section{Programme Activity 1: \\ Sexual and Gender-based Violence Workshops}

Against the backdrop of the 16 Days of Activism campaign in 2009, Population Council, in partnership with Ubuntu Institute, hosted a sexual and genderbased violence workshop for Traditional Leaders in Johannesburg in November 2009 to determine their perceptions of and attitudes towards SGBV and what roles they believe they can play in fighting SGBV in KwaZulu-Natal, North West and Limpopo.

\section{The main goals of the workshop were to:}

- elicit the Traditional Leaders' personal understanding and perceptions of gender-based violence;

- understand community cultural norms, values and social practices in relation to gender-based violence and how communities can be mobilised to fight SGBV; and

- identify structural issues that affect the mitigation of SGBV, such as customary laws, Traditional Court systems and the intersection of these with the constitutional judicial systems.

These findings informed the capacity building interventions needed to strengthen the Traditional Leader's role in SGBV.

\section{Overview of the workshop}

The workshop was structured in such a way that the Traditional Leaders spent most of the time in provincespecific FGDs. However, during the first part of the workshop, Population Council, Ubuntu Institute, and representatives from the provincial departments of health gave presentations on the state of SGBV in the respective provinces, the urgent need for a multi-sectoral approach to addressing SGBV and the key role Traditional Leaders have in fighting SGBV.
Participants were divided into province-specific focus groups which were led by facilitators using a structured questionnaire (see pg 6). A feedback session followed which synthesised the discussions and outcomes as outlined below.

\section{Feedback from focus group discussions}

\section{Understanding of gender-based violence}

- Almost all Traditional Leaders described gender-based violence as any kind of violence against women, the disabled, children and sometimes men. It takes many forms: physical abuse, sexual abuse as a result of alcohol abuse, and emotional abuse due to the economic situation. Traditional Leaders acknowledged that gender-based violence mostly affects women more than men. However, they seemed to know little about SGBV against young boys, for example sodomy, and also complained that the definition of SGBV usually pertains to women and not men.

"In our African culture a woman is not supposed to be abused and beaten. That is un-African. Our culture respects our women." (Focus group discussion respondent,
KwaZulu-Natal Traditional Leader).

- Traditional Leaders believed that it was "un-African" for a man to beat his wife or partner. "In our African culture a woman is not supposed to be abused and beaten. That is un-African. Our culture respects our women." (Focus group discussion respondent, KwaZulu-Natal Traditional Leader). 
- Lack of understanding of women's rights and knowledge about the Domestic Violence Act was evident amongst participants. More education is required to balance traditional views and western/constitutional views.

\section{Personal understanding and perception of GBV}

Information gathered from the workshop will inform future social mobilisation interventions and capacity building activities. The FGDs confirmed the patriarchal nature of Traditional Leadership. The majority of the Traditional Leaders were men and the contributions by female Traditional Leaders were often overruled. Patriarchy was used to justify gender-based violence and women were held responsible for GBV, with little acknowledgment of the role that men play. Wearing of short skirts or refusing to have sex with your partner were cited as examples that pushed men to abuse their partners. The idea of disclosing one's status is foreign, which is why people infected with HIV do not easily disclose their status. Group counselling on HIV worked better in one community, and people did not have to disclose their status.

\section{Cultural norms, values and cultural practices}

The powers of the Traditional Leaders have been eroded; Traditional Leaders no longer have a clear role in their community and find it hard to rule. "Ukubuthwa" a traditional practice where young men in particular learn the code of ethics of the community from their elders, created security within the communities. According to this practice, each age group has its own "police" that are responsible for it. If a member was out of line the "police" would deal with them. Ukubuthwa is an example of the many traditional practices that played an important role in providing social cohesion that has been done away with. Nothing has replaced these traditional practices.

\section{Traditional Leaders no longer have}

a clear role in their community and find it hard to rule.

"Ukubuthwa" a traditional practice where young men in particular learn the code of ethics of the community from their elders, created security within the communities.

There is a firm belief in virginity testing, but girls cannot be forced to undergo testing as they insist that they have "rights". Initiation schools and the rite to passage are some examples of other cultural practices that were effective in teaching about sexuality, and which would have prevented the spread of HIV are no longer practiced and the Traditional Leaders do not have a way to enforce these.

\section{Causes of gender-based violence}

Respondents highlighted several factors that cause GBV such as poverty, abuse of older women for pension money, and men who are unable to provide for their families and who become violent as a way to compensate for their feelings of low self-worth. However, the belief that women bring about violence on themselves was concerning: wearing mini-skirts; abusing alcohol and drugs; refusing their partners conjugal rights; and lack of respect of customary laws, were some examples given. 


\section{Gender-based violence and HIV}

Gender-based violence is said to contribute to the spread of HIV in various ways:

- Women who ask their partners to get tested for HIV are abused when their partners do not want to test.

- The myth that sleeping with a virgin cures HIV still persists and so men rape young women who are virgins.

- Older, sexually experienced, and sometimes HIVpositive men take young women who are still in school as their wives.

\section{Current mechanisms of dealing with gender-}

\section{based violence}

Survivors (for the purposes of this report the terms survivors and victims are used interchangeably) of GBV who are between 3-15 years old are taken to the Traditional Court which is usually made up of a council of Traditional Leaders or chiefs. These councils are found in most traditional authorities and adjudicate on cases. Perpetrators pay a penalty of three to four cows depending on the severity of the case. Cases that are too complicated for the Traditional Court are usually referred to the higher court systems, for example where evidence is either not conclusive or where there is no evidence but an allegation has been made and a case reported. Traditional Court councils are usually based on a retributive justice system. The focus of the fine is on the family, rather than the individual.

Traditional Leaders said they had more success dealing with cases where the entire family is involved and where the family can hold an individual accountable as opposed to a punitive system that punishes the individual, who may repeat the offense and has no family to hold him accountable.
Stigma towards victims of gender-based violence is particularly prevalent according to Traditional Leaders and, as a result, victims do not always report the abuse. When the abuse is reported, the police are not always able to successfully investigate the cases and, when they do, perpetrators are said to bribe their way out. This in turn discourages victims from reporting abuse. The current lack of consultation between the police, the judicial system and the Traditional Courts results in perpetrators defying the Traditional Court ruling. They are often discharged by the judiciary and this renders the Traditional Leaders' authority null and void.

\section{The current lack of consultation between the police, the judicial system and the Traditional Courts results in perpetrators defying the Traditional Court ruling.}

\section{Potential role}

There was a great deal of discussion about the role that Traditional Leaders play in their communities and how they can use cultural platforms at community level to address SGBV.

Some of the roles that Traditional Leaders said they played in their communities are:

- As custodians and protectors of African culture, customs and values, Traditional Leaders can promote positive values within the community and advocate for the respect of women and children.

- They are symbols of unity within a community and maintain social cohesion. The victimisation of SGBV victims is a disruption to that social order and cohesion. 
- They play an important advisory role to government and feel that they are well-positioned to help support policy development on various socio-economic and socio-cultural issues that affect people at grassroots level.

- Traditional Leaders officiate over customary law courts in rural areas, and maintain law and order by imposing fines on perpetrators of SGBV. The Traditional Leaders feel that they could work more closely with police and medical service providers to support cases and victims of SGBV by sensitising the community and urging them to report SGBV incidents. Traditional Leaders can also ensure that there are peer supporters within communities to provide support to victims.

- At community level, they are able to reach many members of the community through traditional forums such as "imbizo"' (a summons), "ebandleni" (audience with elders) or "lekgotla" (dialogue), and which can be used to drive SGBV campaigns at a grassroots level.

\section{Structural norms}

At a structural level, the programme sought to address issues surrounding Traditional Court councils, and relationships between government and Traditional Leaders. It also explored how policy development and implementation could be informed by localised context of SGBV. Traditional Leaders cited the need for government, local municipalities and communities to respect Traditional Leaders and recognise their authority.

Genuine involvement and partnership with Traditional Leaders from conceptualisation of programmes to implementation by the police, local municipalities and government were suggested as the first step in the right direction. It was agreed that the frequent meetings between the magistrates courts and the Traditional Leaders were necessary, as they are an opportunity to clarify updates on new legislation and the role of Traditional Leaders.

\section{Partnerships between Traditional Leaders and non-government organisations}

It seemed that the relationship between Traditional Leaders and the NGOs in their communities is a tenuous one. Traditional Leaders felt that programmes introduced by outsiders do not succeed. Workshops organised by NGOs are usually held away from communities, and the use of English alienated participants. In addition, the style of the workshops means that there is not much contribution from members and this discourages genuine participation.

\section{Partnerships between Traditional Leaders and government}

Clinics are far from communities, making it difficult for victims to get the help they urgently need. Communication with victims is in English or by means of a letter which the victim does not understand. She therefore does not appear in court and, as a result, the case is thrown out.

Overall, Traditional Leaders felt disempowered by the system. Funding is never directly with the Traditional Leaders, making it difficult for them to implement programmes in their communities. The lack of clarity on the role of Traditional Leaders and government structures like the police and the justice system also render Traditional Leaders powerless. However, Traditional Leaders do take some responsibility for the role they play in how they are perceived. 


\section{Key outcomes of discussions}

\section{Relationship building with government institutions}

- Traditional Leaders need stronger relationships with government. There are tensions between local government at an administrative level and Traditional Leaders who are outside of government. This tension is attributed to the lack of consultation by local government when implementing projects which effectively bypass the Traditional Leaders. This negatively impacts on service delivery as Traditional Leaders are then perceived as obstacles to implementation. At a structural level, Traditional Leaders advocate for improved relations with government and development of operational guidelines to mitigate any tension.

- Traditional Leaders suggested that there should be stronger ties between themselves and the court systems/magistrates for better referral and so that cases are managed more effectively.

- A need for stronger links with the Department of Health was also cited to improve prompt referral to and from the health services for ongoing support in the community.

\section{Capacity building}

Traditional Leaders feel they are not fully capacitated to respond to SGBV cases in their communities. This is despite capacity building sessions where 60 Traditional Leaders were trained on gender-based violence after signing a Memorandum of Understanding between the National House of Traditional Leaders (NHTL), the Department of Justice and the National Prosecuting Authority earlier this year. Each province, with the exception of the Western Cape, has a Provincial House of Traditional Leaders with a clear, province-specific vision and mission that promotes autonomy, transparency and institutions that are gender sensitive. NHTL unifies the Traditional Leadership and guides it on protecting diverse cultural practices.

The NHTL was inaugurated on 18 April 1997. It was originally called the National Council of Traditional Leaders (NCTL) but the name changed in 1998, to the National House of Traditional Leaders. In his inaugural address to the NHTL, former South African President, Mr Nelson Mandela, said: "When the new constitution was drafted, there were concerns that it did not define in sufficient detail the status and role of Traditional Leaders and that it did not, unlike the interim constitution, oblige government to set up this council." The NHTL is an organisation that stands for transformation and equality amongst everyone.

\section{The NHTL is an organisation that}

\section{stands for transformation}

\section{and equality amongst everyone.}

Ongoing capacity building needs to be conducted with Traditional Leaders so that they can deal with SGBV cases on merit and not based on their personal values and attitude. Once confident and skilled enough, Traditional Leaders may be able to cascade the knowledge and better respond to the interventions at community level. Interactive workshops were cited as the preferred training method by the Traditional Leaders.

Resources would need to be deployed to the Traditional Leaders, or at least they would like to be actively involved in the management of the budget from the planning stage through to implementation and evaluation. Examples of the topics to be included in training were women's empowerment, how to give information to potential victims, informing victims about court procedures, 
Once confident and skilled enough, Traditional Leaders may be able to cascade the knowledge and better respond to the interventions at community level. Interactive workshops were cited as the preferred training method by the Traditional Leaders.

reinforcing customary laws that provide discipline, doorto-door campaigns, and information, education and communication (IEC) material on SGBV, to name a few.

In terms of women's empowerment, Traditional Leaders would like to align themselves with the goal of the NHTL which resolved to empower women in rural areas because they are the ones who bear the brunt of poverty, abuse and other related challenges facing women. The empowerment of women is key since women tend to share information, empower others, implement and make it possible for a village to achieve through their experiences.

The powers of Traditional Leaders have steadily been eroded by democracy and while Traditional Leaders are still respected by their communities, they would like more government support for their programmes. Specifically, they are hoping Parliament will successfully implement the Traditional Councils Bill which will give Traditional Leaders more power in the long term. The role of Traditional Leaders as described in the White Paper on Traditional Leadership and the Framework Act regarding safety and security is clear and practical.
The government has adopted a four pillar approach to crime which sets out different areas in which crime prevention should be developed. This model is intended to provide a basis for the development of crime prevention initiatives at provincial and municipal levels, as well as through civil society initiatives.

- $\quad$ Pillar 1: The criminal justice process aims to make the criminal justice system more efficient and effective by providing a clear deterrent for criminals and by reducing the risks of re-offending.

- Pillar 2: Reducing crime through environmental design focuses on designing systems to reduce the opportunity for crime and increase the ease of detection and identification of criminals.

- $\quad$ Pillar 3: Public values and education has to do with initiatives aimed at changing the way communities react to crime and violence. It involves programmes which utilise public education and information to facilitate meaningful citizen participation in crime prevention.

- $\quad$ Pillar 4: Trans-national crime programmes aim to improve controls over cross-border traffic related to crime.

Traditional Leaders would like to be more actively involved in implementing the four pillar approach in order to play a more meaningful role in crime prevention, including SGBV. The approach has made fighting crime a community matter where everyone can contribute to eradicating crime. 
- Traditional Leaders noted the need for closer monitoring of taverns (community bottle stores) to ensure that they abide by the operating hours prescribed by the licence granted. Some communities have up to 10 taverns/shebeens in a small area and alcohol is readily available. They confirmed that SGBV cases have a strong link to alcohol-related abuse and drugs.

- Traditional Leaders acknowledged the invaluable contribution of NGOs, donors and other key stakeholders in fighting SGBV in their communities and would like to work more closely with them.

- Traditional Leaders requested support for better documentation of their activities. Some Traditional Courts do not keep proper records of cases and this makes monitoring and evaluation very difficult. 


\section{Programme Activity 2: Capacity Building}

One hundred and twenty six Traditional Leaders from the three provinces involved in the programme attended capacity building sessions, together with their indunas or Traditional Council members. The information sessions highlighted the extent of sexual assault, PMTCT, GBV and HIV and AIDS prevalence in each province.

Workshops were held in each of the provinces and Traditional Leaders were identified and invited through the House of Traditional Leaders and CONTRALESA. A consultant who is a traditional leader was contracted by Population Council to facilitate the identification of Traditional Leaders for the FGDs and capacity building workshops. This strategy was used to bypass protocols within the patriarchal structures which often impede access to Traditional Leaders.

\section{Capacity building workshops}

The National Department of Health has identified 18 priority districts in South Africa's nine provinces which need to improve maternal, neonatal, child, women's health (MNCWH) and nutrition services. The priority districts were identified because of their poor health status, poor health service delivery and poor access to health services. Three capacity building workshops were thus held in the priority districts of KwaZulu-Natal, North West and Limpopo.

In KwaZulu-Natal the workshop was held in Ugu District, hosted by the senior chief of KwaNdelu Traditional Council under the Umzumbe Municipality. Ugu is one of the 11 districts in KwaZulu-Natal with high SGBV cases and the majority of its 704001 population speak IsiZulu (2001 Census) ${ }^{7}$. The workshop was attended by 36 Traditional
Leaders, 11 of whom were female. The female Traditional Leaders in KwaZulu-Natal participated actively. This was extremely positive and future interventions should focus on female Traditional Leaders (that is the wives of Traditional Leaders) as key players in the fight against SGBV and HIV and AIDS in South Africa.

\section{The priority districts were identified because of their poor health status, poor health service delivery and poor access to health services.}

In the North West Province the workshop was hosted by Senior Chief Nawa at the Traditional Authority in Lebotloane in the Moretele sub-district. Moretele is a local municipality in the Bojanala Platinum District Municipality with a population of $180000^{8}$. Fifty people attended, one of whom was female.

The Limpopo workshop was held at the Maruleng District and hosted by Senior Chief Kgosi Chiloane and Hlokomela, an NGO that provides antiretrovirals and HIV counselling and testing to the farming community. The Maruleng Municipality has a population of 107247 39, 7\% of whom are between 15-34 years old ${ }^{9}$. The municipality is primarily populated by seasonal farmers who are highly mobile. The site was deliberately selected to reach the farming community, including the farm owners, to ensure buy-in and collaboration. Forty Traditional Leaders attended, three of whom were female. 
The presentations and training were conducted over a period of two days by representatives from the Department of Health, Department of Justice and experts from human rights organisations and community policing forums, among others. The objective of the training was to share information on the magnitude of SGBV in rural communities, the role of Traditional Leaders in the prevention and management of SGBV, the legal perspective of Traditional Leadership, and the human rights perspective on SGBV.

\section{Presentations by the Department of Health}

The presentations by the DOH were made by

Mr R Phili, Director HIV and AIDS, KwaZulu-Natal; Ms Matshediso Sentle, Assistant Manager Community Health Services: Moretele sub-district, North West; and Mr Diketane: Manager NGO partner, Limpopo. The presentations highlighted:

- Statistical facts about the HIV and AIDS prevalence in the three provinces in comparison with the rest of the country.

- Some of the ways in which the virus is transmitted and the demand for healthcare provision.

- Behavioural issues that exacerbate the high prevalence rate such as intergenerational sex $^{10}$, poor antenatal check-ups and multiple concurrent partners.

- The role that Traditional Leaders should play in encouraging women to attend antenatal follow-up at clinics to promote maternal health care and reduce the infection rate among newborn and unborn babies.

- Encouraging community members to adopt behavioural changes that will reduce prevalence through HIV counselling and testing (HCT).

- Issues around SGBV, the importance of reporting SGBV cases, the relationship between the police and health-care facilities, and the process of acquiring medical evidence in the event of a sexual assault case.

- Thirty six percent of rape cases are children below the age of 15, and participants, particularly the Traditional Leaders were asked to take action to reduce the statistic by engaging their communities in dialogue about SGBV.

- Sexually transmitted infections (STIs) and the importance of treatment to avoid infecting unborn or newly born babies and re-infection.

- The highest incidence of STIs occurs in women between the ages of 15-29 and in men between 20-24.

- The link between SGBV and HIV.

- SGBV is not only about women being abused by men. Men also abuse each other and can be abused.

- The cause of sexual aggression vis-à-vis current legislation in South Africa and the Domestic Violence Act of 1999.

- The existence of toll-free numbers to report or for assistance in matters of SGBV and child abuse.

- The need for community education by Traditional Leaders on sexual reproductive health (SRH).

- The distinction between gender and sex and the definition of GBV. Seroprevalence data from 2008 was used for Limpopo districts to demonstrate the severity of the HIV prevalence rate, shocking the meeting into accepting that Traditional Leaders need to take immediate steps to actively engage their communities in reducing HIV prevalence.

- Stereotypes and beliefs about the behaviours that delay people seeking medical attention. The old saying that men do not cry or show vulnerability was cited as one of the reasons why men often do not go to clinics for medical assistance.

- The cultural view that encourages male promiscuity is one of many issues that perpetuate the high HIV prevalence rate. Traditional polygamy which "delineated the sexual relationship between a man with his wives is misunderstood and incorrectly 
applied by men who have more than one sexual partner outside their marriage.

- The disempowerment of women in the social and cultural arena helps to spread the virus further as women are often not in a position to request or demand safer sex from their partners.

- Another reason contributing to the increasing rate of HIV is that people continue to be in denial about the disease and neglect seeking professional advice and treatment for STIs.

- The role of Traditional Leaders as custodians of culture and the need to influence attitude and behaviour change by acknowledging the severity of the prevalence rate and by taking action to reduce it.

\section{Farm owners revealed that the} high levels of unemployment have led to senior staff on the farms, such as supervisors and managers, demanding sexual favours in return for employment.

\section{Farm workers: The employer's perspective}

The presentation from farm owners revealed that high levels of unemployment have led to senior staff on the farms, such as supervisors and managers, demanding sexual favours in return for employment.

Farm owners further stated that there is often not enough housing for the number of employees and, in some cases, this has led to seasonal employees entering into sexual relationships with partners lodging in the vicinity of the farms. This increases the incidence of multiple concurrent partners, facilitating the spread of HIV.
The presentation said that most of the problems encountered on farms were caused by women and alcohol abuse. It was further noted that in cases of domestic violence, the employers encourage the victims to report the matter to the police. The presenter explained that farm owners release workers to attend Traditional Court if and when summoned by the chief of the area; thus supporting Traditional Leaders. Proof of the summons is usually required.

\section{Presentations by the Department of Justice: The legal perspective}

The DOJ in conjunction with Mr Booker Mohlaba from private law firm, Mohlaba \& Moshoana Inc and Mr Howard Msomi, Chairperson of the Community Policing Forum in the Umzumbe Municipality presented the legal perspective of Traditional Leadership. The presentations began by explaining the different types of abuse suffered by spouses including physical, emotional, financial and psychological abuse, and confirmed that men also suffer from abuse. They also:

- Explained that generally men do not report abuse and that courts usually preside over cases where women are the victims of abuse.

- Explained the different forms of sexual abuse and it was noted that Traditional Leaders have a role to play in presiding over cases of indecent assault.

- Pointed out that there was no acceptable reason for allowing incidences of indecent assault to be downplayed resulting in the assault becomes chronic and/or severe and that Traditional Leaders should encourage families to report cases of indecent assault.

- Spoke about the key role that Traditional Leaders have in reducing the backlog of cases at the Magistrates Court by presiding over minor cases. 
- Identified the opportunity for Traditional Leaders to form a relationship with the Magistrates Courts so that rulings of the Traditional Courts could be more successfully enforced with the assistance of the Magistrates Court.

- Gave a brief background of the Traditional Courts Bill and the role of Traditional Leaders in South Africa from the Apartheid Era ${ }^{11}$.

- Noted that the Traditional Court's power and in essence that of Traditional Leaders was first eroded in 1968 when the Commissioners Courts run by the Bantu Affairs Commissioners were introduced.

- Tabled an outline of the progression of Commissioners Courts to Magistrates Courts while alluding to the fact that people in communities favoured the Traditional Courts less and less for various reasons, including the lack of enforcement mechanisms for Traditional Court rulings.

- Noted that the Magistrates Courts primarily had jurisdiction over criminal cases and to a lesser extent civil cases, and that magistrates often act as mediators in civil disputes. They only advise on a way forward and disputing parties are not compelled to follow this advice.

- Pointed out that the rulings of Traditional Courts are often not adhered to and the police do not take issues like stock theft and disputes with neighbours seriously. The link between "minor" crimes and SGBV is often ignored. In other words the likelihood of assault and violence during crime is unlikely to be explored.

- Highlighted the importance of the Traditional Courts Bill as the first step towards reinstating the powers of Traditional Courts and, in turn, of Traditional Leadership structures.

- Discussed how the Bill provides for the enforcement of sentences and further strengthens the role of the Traditional Courts in presiding over civil matters.

- Presented a background on the establishment of the Community Policing Forum (CPF) and gave a brief overview of its objectives.

\section{...rulings of Traditional Courts are}

\section{often not adhered to and the}

\section{police do not take issues like stock}

\section{theft and disputes with neighbours}

\section{seriously. The link between \\ "minor" crimes and \\ SGBV is often ignored.}

- Emphasised the need to establish a CPF at every police station and that the existence of CPFs aims to increase the accountability of the police to the community, positively impact on service delivery and crime reduction.

- Highlighted the fact that the presence of Traditional Leaders in CPF was rare and almost non-existent, thus hindering the authority Traditional Leaders have in their communities.

- Explained that the purpose of such forums is to influence policy and that it would be in the best interests of the Traditional Leaders if they assumed a more active, participatory role in forums such as CPF.

- Observed that one way to effectively impact on crime statistics in the communities was to return to traditional social orders/peer groups where children receive cultural and traditional education that 
supplement other forms of education.

- Emphasized that being part of such a peer group instils a feeling of "brotherhood" among the members and helps support each other emotionally and socially.

\section{A human rights perspective: Presented by} University of Pretoria Centre for the Study of AIDS

Mr Erens Malatjie from the University of Pretoria Centre for the Study of AIDS gave a presentation on human rights and its link with GBV. The presentation highlighted the Constitution of South Africa and specifically the Bill of Rights. The presentation mentioned that rights come with responsibilities and limitations and emphasised the importance of respecting peoples' rights. The presentation further defined GBV and elaborated on the different forms of violence - sexual, emotional and economic violence among others. In addition, the presentation emphasised one's right to counselling before and after being tested for HIV and condemned stigmatisation and discrimination of people infected or affected by HIV and AIDS.

The question and answer session concluded that people are often not aware of their rights and therefore not able to identify when they are being violated. It was therefore argued that any educational exercises in the second phase of the project must include a section on human rights, particularly women and children's rights.

\section{Traditional Leaders' response to SGBV}

The responses of Traditional Leaders to the various presentations revealed that:

- Traditional Leaders are not sure of the types of cases they should try or the limits of their powers in terms of sentencing people.
- Often rulings of the Traditional Courts are not adhered to and members of the community use the Traditional Courts less and less.

- Although the Bill makes provision for a stronger female presence in Traditional Courts, in reality there are still cultural issues that hinder the participation of women in Traditional Courts. One example cited was that traditionally women are supposed to be passive observers rather than active participants.

- The Bill does not provide for the demarcation of cases to be tried in the Traditional Courts as opposed to the Magistrates Court. In instances where a criminal offence will result in long-term incarceration it makes sense that it be tried by the Magistrates Court.

- The Bill has been before Parliament since 2004 and chiefs must make do with the status quo, until such time as the Bill is passed and enacted into law. However, the Bill has important implications for chiefs as it seeks to restore their power at community level and Traditional Leaders hope that it will not take much longer for the Bill to be passed.

\section{The Bill does not provide for the demarcation of cases to be tried in the Traditional Courts as} opposed to the Magistrates Court. 


\section{Summary of Findings and Recommendations}

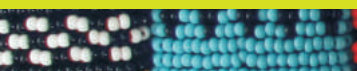 \\ Participation of female Traditional}

\section{Leaders}

There were few female Traditional Leaders at the workshops and, with the exception of KwaZulu-Natal, about two female Traditional Leaders per province participated in discussions. This gives insight into the level of participation of females during Traditional Council sittings and community dialogues. However women play a key role in ensuring that incidents of SGBV are reported and a gender-balanced view is presented at community courts. It is thus recommended that going forward, interventions should focus on female Traditional Leaders (wives of Traditional Leaders), as key players in the fight against SGBV and HIV and AIDS in South Africa. Their role as "mothers of the nation" needs strengthening and support.

\section{Capacity Development of Traditional}

\section{Leaders}

Traditional Leaders need further training on sexual reproductive health issues and dealing with SGBV. In a PMTCT discussion and training in Limpopo, a facilitator asked a female traditional leader the question, "what feeds an unborn baby in the womb of the parent during pregnancy?" The alarming response from a female Traditional Leader was "an unborn baby feeds directly from the father's sperm found in the mother's womb during pregnancy."

Further training on sexual reproductive health, PMTCT, SGBV and access to services, human rights and governance is required and linking these topics to sociocultural contexts is important. Traditional Leaders serving in Traditional Courts in particular need to be trained to increase their understanding of SGBV, access to services and to fight stigma, myths and misconceptions around SGBV.

\section{Institutional capacity of Traditional}

\section{Authority}

The Traditional Courts lack structures that promote reporting of SGBV cases. As evidenced by the low turnout of women at the workshops, this in essence impacts on the ability of children, especially young girls, to report incidents of SGBV. In addition, the Traditional Leaders mentioned that Traditional Courts are not courts of record and in instances where a ruling is appealed the Magistrates Court, the proceedings are sometimes delayed by a lack of records. Moreover, the Traditional Leaders lamented the absence of an instrument that compels perpetrators to attend Traditional Court sessions and that enforces the sentences passed. It is therefore recommended that the institutional capacity of the Traditional Authority be improved through partnerships with organisations such as the DOJ and SAPS. These partnerships will enable the strengthening of Traditional Courts.

\section{It is therefore recommended that} the institutional capacity of the Traditional Authority be improved through partnerships with organisations such as the DOJ and SAPS. These partnerships will enable the strengthening of Traditional Courts. 


\section{Education on human rights and the rights of women and children}

One of the stated reasons why SGBV cases are not reported is that victims are not always aware of their rights and thus cannot identify when their rights are being violated. However there are instances where people know their rights but continue to violate the rights of the next person, thus taking advantage of the ignorant populace. It is thus recommended that Traditional Leaders attend intensive human rights training to better educate their communities, especially on the rights on women and children.

\section{Access to information and information dissemination}

The workshops revealed that Traditional Leaders are not aware of how to access services for SGBV support. Therefore, it is recommended that Traditional Leaders receive guidance on how to refer people in their community to SGBV support services. IEC materials that can be distributed to educate the community are also recommended. Traditional Leaders have a powerful platform through the community imbizos and these can be utilised as a mechanism to share vital information related to SGBV.

\section{Re-introduction of traditional}

\section{practices}

Traditional Leaders expressed concern that the current generation of youth does not appreciate or understand certain traditional practices and therefore tend to exclude themselves from traditional activities. This could result in an absolute erosion of traditions and cultural practices.

African traditional practices teach young people values of respect, tolerance and Ubuntu (caring for others) and these values should be taught at a young age. "Le robjwa le sale meetse", is a North Sotho idiom which means that it is best to teach lessons on respect and culture during the formative years rather than at a later stage.

\section{"Le robjwa le sale meetse", is a North Sotho idiom which means that it is best to teach lessons on respect and culture during the formative years rather than at a later stage.}

\section{Government support for Traditional}

\section{Leaders}

Traditional Leaders cited tensions between themselves and local government/municipalities which hinders growth and service delivery in their communities. The evolution of the Commissioners Courts, the democratisation of South Africa and the extent of westernisation and/or modernisation has effectively left Traditional Leaders aggrieved over the increasing loss of authority over their communities.

It is recommended that the partners in this project facilitate dialogue between the DOJ, Traditional Leaders and other stakeholders including the South African Police Service (SAPS) and the Department of Provincial and Local Government (DPLG) to clarify roles, identify opportunity for partnerships and to pave a way forward towards restoring the integrity and authority of Traditional Leaders in addressing SGBV. Traditional Leaders, despite being undermined by some local government offices, are still respected and loved by the communities they serve and are seen as key leaders in their communities given their historical significance. 


\section{Traditional Courts Bill}

The Traditional Courts Bill has been introduced to restore the powers of Traditional Leaders in South Africa. This Bill is currently being debated. It seeks to give Traditional Leaders executive powers at a community level and to support Traditional Court rulings. However, the workshops revealed that Traditional Leaders were not fully aware of the presence of the Traditional Courts Bill and its importance to sustaining Traditional Authority. It was recommended that the partners in this project help to raise awareness of and educate Traditional Leaders about the Traditional Courts Bill and advocate for the inclusion of women in the new dispensation. This will enable female Traditional Leaders to contribute meaningfully to the legislation and policy issues related to fighting SGBV in South Africa.

\section{Alcohol abuse and intravenous drug}

\section{users}

The Traditional Leaders noted the rise of alcohol consumption and intravenous drug use (IDU) in South Africa and poor management of alcohol licenses at community level that allows youth easy access, with no proper regulations and resources to monitor license holders. South Africa has one of the highest per capita alcohol consumption rates in the world ${ }^{12}$ and research has shown a strong link between alcohol abuse and SGBV. There is thus a tremendous opportunity for the programme to include and to address drug and alcohol abuse and its link to SGBV.

\section{South Africa has one of the highest per capita alcohol} consumption rates in the world ${ }^{12}$ and research has shown

a strong link between alcohol abuse and SGBV. 


\section{Conclusion}

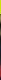

The overarching goal of the programme was to explore the role of Traditional Leaders in addressing SGBV at community level. Traditional Leaders in three South African provinces (KwaZulu-Natal, Limpopo and North West) participated in the programme entitled "Socio-Cultural Approaches to Addressing Sexual and Gender-based Violence." Provinces with high levels of SGBV and HIV and AIDS were targeted.

The programme provided capacity building for 126 Traditional Leaders, led social mobilization campaigns to address SGBV at community level and which reached over 600 people in three months, and conducted a baseline study investigating Traditional Leaders' perceptions of SGBV at an individual, community and structural level.

All three provinces targeted have strong Traditional Leadership that has been largely untapped insofar as addressing SGBV and HIV and AIDS. Traditional Leaders have influence in rural, underserved areas of South Africa as they are considered the "custodians of African culture" and play various leadership roles in the communities they serve. The Population Council and Ubuntu Institute recognised this gap and enlisted the support and partnership of national government departments, namely $\mathrm{DOH}$ and DOJ to partner with them to drive this SGBV programme.

The outcomes and recommendations of the programme were as follows:

- There is a need to strengthen Traditional Court systems that deal with SGBV at a community level;

- The support of female Traditional Leaders should be enlisted to help with SGBV prevention and support for young girls;

\section{Traditional Leaders have influence}

in rural, underserved areas of South Africa as they are considered the "custodians of African culture".

- Traditional Leaders should be linked with the justice system, the police and health system as well as with the farming community to improving their monitoring and SGBV programming quality;

- Relationships of Traditional Leadership with local governments should be strengthened;

- Traditional Leaders should be provided with access to information about SGBV that can be distributed to the community;

- Best practices should be documented;

- There is a need to further strengthen capacity building for Traditional Leaders and their institutions to more effectively respond to community needs to address SGBV.

This report will be disseminated nationally to stakeholders as well as to an international audience in order to share the findings of the programme. The engagement of Traditional Leaders in the fight against SGBV and HIV and AIDS is long overdue and is an important part of achieving both the HIV and AIDS National Strategic Plan and the Domestic Violence Act. 


\section{Bibliography}

1. Traditional Leaders Fighting HIV AND AIDS in Southern Africa - A four country study (Swaziland, Botswana, Lesotho and South Africa), Ubuntu Institute, 2008

2. South African National HIV and AIDS strategic plan, 2007-20011

3. Statistical Release: Mid Year Population Estimates, July 2009, Statistics South Africa

3. R. Jewkes, K. Dunkle, M. Nduna, and N. Shai, "Intimate Partner Violence, Relationship Gender Power Inequity, and Incidence of HIV Infection in Young Women in South Africa: A Cohort Study," in The Lancet (in press)

4. World Health Organisation. (2002) Sexual Violence. In: World Report on Violence and Health, World Health Organisation, Geneva

5. Sexual and Gender Based Violence in Africa: Literature Review, February 2008, Population Council

6. From Evidence to Action-Assessing Need, Achieving Results, Population Council Annual Report, 2008

7. http://en.wikipedia.org/wiki/Ugu_District_Municipality 1 February 2010; 16h57

8. http://en.wikipedia.org/wiki/Moretele; 23 January 2010; 21h02

http://en.wikipedia.org/wiki/Traditional_authority\#Traditional_leaders 1 February 2010; 16 h00

9. http://www.maruleng.gov.za/index.php?page=council_leaders 23 January 2010; 21 h06

10. Intergenerational sex: the concept of teenagers entering into transactional sex with older partners commonly referred to as "sugar-daddies" and "sugar-mommies"

11. "Apartheid: An official policy of racial segregation formerly practiced in the Republic of South Africa, involving political, legal and economic discrimination against non-whites" http://www.answers.com/topic/apartheid; 12h00, 29 January 2010

12. http://www.info.gov.za/speeches/2007/08010814451001.htm 2 February 2010, 14h53 





\section{Population Council}

Unit 002 \& 003 Dalefern Office Park

PO Box 411744

284 Oak Avenue

Craighall

Ferndale

2024

Randburg

2194

Telephone: +27 11781 7590/7594

Fax: +27 113261483

Johannesburg

Email: info.joburg@popcouncil.org 